\title{
Syphilis presenting with moth-eaten alopecia
}

\author{
Meng Yin Wu MD, Jun Li MD
}

Cite as: CMAJ 2021 January 25;193:E126. doi: 10.1503/cmaj.200894

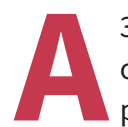

38-year-old man presented to the dermatology department with a 6-month history of progressive hair loss without scalp pruritus or pain. The lesions were spread across the patient's scalp, giving the appearance of diffuse moth-eaten patches of nonscarring and noninflammatory alopecia, with blurred edges and irregular size (Figure 1A). Three months before, the patient had nonpruritic erythema across his trunk and limbs, which spontaneously resolved within 10 weeks. He reported having had unprotected sex 6 months before and denied any history of intravenous drug use.

Serological evaluation for syphilis showed a positive $(1: 64$, normal [negative] $\leq 1: 8)$ rapid plasma reagin (RPR) test and a positive fluorescent treponemal antibody absorption test, supporting our diagnosis of secondary syphilis. Results were negative for HIV testing. We prescribed penicillin therapy administered intramuscularly (3 weekly doses of 2.4 million $U$ ) and, 3 months later, his hair had regrown (Figure 1B) and an RPR test showed a titer of 1:8. At 1 year, his RPR titer had decreased to 1:1.

The incidence of syphilis is rising in Canada., ${ }^{1,2}$ Moth-eaten alopecia, without any scars or pruritus, has been described in about $3 \%-7 \%$ of patients with secondary syphilis. ${ }^{3}$ Syphilitic alopecia may be patchy, diffuse or both, but it is predominantly localized in the occipital and parietal regions. Hair loss may be accompanied with generalized, nonpruritic erythema, a preceding history of genital chancre or painless generalized lymphadenopathy. ${ }^{4}$ In patients with a positive result for serology testing, consider a diagnosis of essential syphilitic alopecia when alopecia remains the only manifestation of syphilis, and symptomatic syphilitic alopecia when hair loss is accompanied by other findings of syphilis. ${ }^{3}$

Clinical signs on trichoscopy suggestive of alternative diagnoses include the presence of "exclamation point hairs," suggesting alopecia areata, and "comma hair," suggesting tinea capitis. ${ }^{5}$
A history of hair pulling and irregularly broken hairs under trichoscopy suggests trichotillomania. ${ }^{5}$

\section{References}

1. Choudhri Y, Miller J, Sandhu J, et al. Infectious and congenital syphilis in Canada, 2010-2015. Can Commun Dis Rep 2018;44:43-8.

2. Infectious syphilis cases reported in Canada 2009-2018 [infographic]. Can Commun Dis Rep 2019;45-11:302. Available: www.canada.ca/en/public-health/services/ reports-publications/canada-communicable-disease-report-ccdr/monthly-issue /2019-45/issue-11-november-7-2019/article-5-infectious-syphilis-canada-2009-2018. html (accessed 2020 June 18).

3. Piraccini BM, Broccoli A, Starace M, et al. Hair and scalp manifestations in secondary syphilis: epidemiology, clinical features and trichoscopy. Dermatology 2015;231:171-6.

4. Li S, Wu L. Hair loss and lymphadenopathy. BMJ 2019;366:14555.

5. Rudnicka L, Rakowska A, Kerzeja M, et al. Hair shafts in trichoscopy: clues for diagnosis of hair and scalp diseases. Dermatol Clin 2013;31:695-708.

\section{Competing interests: None declared.}

This article has been peer reviewed.

The authors have obtained patient consent.

Affiliation: Department of Dermatology, Peking Union Medical College Hospital, Chinese Academy of Medical Sciences and Peking Union Medical College, Beijing, China
Content licence: This is an Open Access article distributed in accordance with the terms of the Creative Commons Attribution (CC BY-NC-ND 4.0) licence, which permits use, distribution and reproduction in any medium, provided that the original publication is properly cited, the use is noncommercial (i.e., research or educational use), and no modifications or adaptations are made. See: https://creativecommons.org/licenses/by-nc-nd/4.0/

Correspondence to: Jun Li, lijun35@hotmail.com 